\title{
Differential Appearance of $T$ Cell Subsets in the Large and Small Intestine of Neonatal Mice
}

\author{
SHEREE KUO, AUSTIN EL GUINDY, CHETAN M. PANWALA, PATRICIA M. HAGAN, AND \\ VICTORIA CAMERINI \\ Department of Pediatrics and the Beirne B. Carter Center for Immunology Research, University of \\ Virginia Health Sciences Center, Charlottesville, VA 22908, U.S.A. [S.K., P.M.H., V.C.]; and the \\ Department of Microbiology and Immunology, University of California Los Angeles, CA 90095, U.S.A. \\ [A.E.G., C.M.P.]
}

\begin{abstract}
ABST
We examined the appearance of intestinal intraepithelial lym-
phocytes (IEL) during the first 12 wk of life to gain insight into
postnatal factors that contribute to the differences found between
IEL in the large and small intestines of adult mice. Intestinal T
cells were very infrequent at birth, but increased in number in the
large and small intestine during the first 4 wk of life and then
stabilized. The small intestinal epithelium at 2 wk of age con-
tained mostly T cell receptor (TCR) $\alpha \beta+$, CD2 + T cells, unlike
IEL in adult mice, which were composed of nearly equal pro-
portions of CD2-, TCR $\alpha \beta+$ and TCR $\gamma \delta+$ cells. Between 2
and 3 wk of age, TCR $\gamma \delta+$, CD2 - IEL increased greatly in the
small intestine, whereas TCR $\alpha \beta+$ cells expressing CD2 de-
creased. By contrast, IEL in the large intestine at 2 and 3 wk of
age were mostly TCR $\alpha \beta+$, CD2 + T cells similar to large
intestinal IEL in adult mice. And finally, the expression of CD69
increased earlier and to higher levels on TCR $\alpha \beta+$ and TCR
$\gamma \delta+$ IEL in the small intestine than in the large intestine. Our
\end{abstract}
results demonstrate that IEL in the large and small intestine are phenotypically similar during suckling and that differences between these populations are established after weaning. Furthermore, the earlier accumulation of IEL with an activated adult IEL phenotype in the small intestine suggests that these $T$ cells mature or expand in the gut and contribute to the maturation of immune function during postnatal life in mice. (Pediatr Res 49: 543-551, 2001)
Abbreviations:
IEL, intraepithelial lymphocytes
LPL, lamina propria lymphocytes
LI-IEL, large intestinal intraepithelial lymphocytes
PE, phycoerythrin
SI-IEL, small intestinal intraepithelial lymphocytes
TCR, T cell receptor

The mucosal immune system of the intestine consists of lymphocytes located in anatomically distinct, but functionally related regions comprising the largest immune effector site in the body. Lymphocytes located within the intestinal epithelium are almost exclusively $\mathrm{T}$ cells, called IEL (1). SI-IEL are mostly CD $8+$, CD $4-$ T cells $(60-70 \%)$, which express a TCR composed of $\gamma$ and $\delta$ chains (TCR $\gamma \delta ; 40-50 \%$ ) or $\alpha$ and $\beta$ chains (TCR $\alpha \beta ; 50-60 \%$ ) (1-3). This is unlike T cells found in peripheral blood and nonmucosal lymphoid organs, which are mostly TCR $\alpha \beta+$ cells that express either CD4 or CD8 in nearly equal proportions. Furthermore, most SI-IEL in mice express a unique form of $\mathrm{CD} 8$, the $\mathrm{CD} 8 \alpha \alpha$ homodimer, whereas the majority of CD8 $+\mathrm{T}$ cells in the lymph node and

Received January 20, 2000; accepted October 13, 2000

Correspondence and reprint requests: Victoria Camerini, M.D., University of Virginia, Department of Pediatrics, Division of Neonatology HSC Box 800386, Charlottesville, VA 22908, U.S.A.; e-mail: vc3p@virginia. edu

Supported by grants from the Robert Wood Johnson Foundation (V.C.), NIH predoctoral training grant GM07185 (C.P.), and Individual National Research Service Award DK09332 (P.H.). spleen express the $\operatorname{CD} 8 \alpha \beta$ heterodimer $(1,4,5)$. Other T cell surface proteins distinguish IEL from peripheral $\mathrm{T}$ cells. The majority of IEL isolated de novo express the activation antigen, $\mathrm{CD} 69$, and a unique mucosal integrin, $\alpha_{\mathrm{E} \beta 7}$, whereas the majority of resting $\mathrm{T}$ cells in the periphery lack these proteins $(6-8)$. Furthermore, most SI-IEL do not express the lymph node homing receptor, CD62L, or the costimulatory ligand, CD2, proteins that are expressed by a majority of $\mathrm{T}$ cells found in lymph node and spleen $(6,7,9)$. Taken together, these data demonstrate that IEL are distinct from $\mathrm{T}$ cells found in nonmucosal sites.

Intestinal mucosal $\mathrm{T}$ cells share some common features, although there are important regional differences between IEL in the small and large intestine and between IEL and T cells found in the lamina propria underlying the epithelium (6, 10-13). The most notable difference between SI-IEL and LI-IEL is the increased proportion of TCR $\gamma \delta+, \mathrm{CD} 8 \alpha \alpha+\mathrm{T}$ cells found among SI-IEL $(40-50 \%)(6,11,12)$. Although TCR $\gamma \delta+$ T cells are present among LI-IEL and T cells in the LPL of both the large and small intestine, they represent a 
smaller portion of these T cells $(5-25 \%)(6,11-13)$. Furthermore, a greater proportion of LI-IEL and LPL in both the large and small intestine express CD62L and CD2, unlike SI-IEL, which are largely negative for these proteins (6). LI-IEL and LPL are therefore intermediate in cell surface phenotype between SI-IEL and $\mathrm{T}$ cells found in nonmucosal sites in the periphery.

The establishment of mucosal $\mathrm{T}$ cells in the small intestine is developmentally regulated and likely coordinated with factors associated with suckling and weaning. Few $\mathrm{T}$ cells are present at birth in the small intestine of mice and rats (14-18). $\mathrm{T}$ cell colonization and expansion in the gut parallels the morphologic development and maturation of the small intestinal mucosa during the early postnatal period, with completion of this process around the third postnatal week (19-22). The paucity of $\mathrm{T}$ cells and the underdeveloped intestinal mucosal surface characteristic of suckling mice and germ-free adult mice suggest that the maturation of the intestine and colonization by IEL are linked, perhaps through epithelial cell and T cell cross-talk, which may be triggered by bacterial flora and food antigens $(21,23,24)$.

Although the establishment of SI-IEL in response to suckling and weaning has been reported previously, no information on the establishment of LI-IEL or the parallel development of these IEL subsets during postnatal life is available (14-18). Furthermore, only limited information is available on the cell surface phenotype of TCR $\alpha \beta+$ and TCR $\gamma \delta+$ IEL during postnatal life compared with IEL of adult mice $(14,17)$. In this report, we present an analysis of the postnatal development of mucosal lymphocytes within the large and small intestine of mice. We found that although colonization of the large and small intestinal epithelium and lamina propria by TCR $\alpha \beta+\mathrm{T}$ cells occurred with a similar kinetics in the postnatal period, the increase in TCR $\gamma \delta+$ IEL occurred selectively in the small intestine at or about the time of weaning. Because the expansion of TCR $\gamma \delta+$ IEL is more specific to the small intestine, it must be more dependent on a factor or factors unique to this location in the gut. These data are consistent with a role for luminal antigens or local maturation of epithelial cells in either the development, maturation, or expansion of TCR $\gamma \delta+$ IEL.

\section{MATERIALS AND METHODS}

Mice. BALB/c mice were originally obtained from Jackson Laboratories (Bar Harbor, ME, U.S.A.) or Simonsen Laboratories (Gilroy, CA, U.S.A.) and bred and maintained at the UCLA vivarium (Los Angeles, CA, U.S.A.) and the University of Virginia Health Sciences Center vivarium (Charlottesville, VA, U.S.A.). Mice were housed on laminar flow racks and under specific pathogen-free conditions. Mice were housed in autoclaved caging and bedding with acidified water and irradiated chow available ad libitum. Pregnant mice were identified and monitored daily until delivery. The day of birth was identified as $\mathrm{d} 0$ of life, and pools of two to six mice, depending on their postnatal age, were examined at weekly intervals. When possible, single litters were used for sequential weekly analysis. All animal protocols were preapproved by the Uni- versity of Virginia and the UCLA Animal Care and Use Committees.

Preparation of $T$ cell populations. Intestinal mucosal lymphocytes were prepared from pools of two to six mice using a modification of a previously published procedure (25). Briefly, the small and large intestines were removed from mice euthanized in accordance with institutional guidelines. The intestines were dissected from their mesentery, and the Peyer's patches and lymphoid aggregates were removed. The intestines were cut longitudinally, washed, and cut into $0.2-$ to $0.5-\mathrm{cm}$ pieces. IEL were prepared after removal of the epithelial layer in $\mathrm{Ca}^{+2}$ - and $\mathrm{Mg}^{+2}$-free Hank's Balanced Salt Solution (GIBCO, BRL Life Technology, Inc, Grand Island, NY, U.S.A.), supplemented with $1 \mathrm{mM}$ DTT (Sigma Chemical Co., St. Louis, MO, U.S.A.). Intestinal pieces were shaken at $37^{\circ} \mathrm{C}$, three times for $20 \mathrm{~min}$ at $250 \mathrm{rpm}$. Cells were collected after each shake and pooled, and mononuclear cells were isolated from the $40 \% / 70 \%$ interface on a discontinuous $20 \% / 40 \% / 70 \%$ Percoll (Pharmacia Biotechnology Inc, Piscataway, NJ, U.S.A.) gradient spun at $900 \times g$ for $20 \mathrm{~min}$. After removal of the epithelial layer, mononuclear cells were released from the lamina propria after finely chopping intestinal segments, followed by incubation in $1.5 \mathrm{mg} / \mathrm{mL}$ of dispase (Sigma Chemical Co.) in RPMI with $10 \%$ FCS for 60 min at $37^{\circ} \mathrm{C}$. LPL cell suspensions were filtered through nylon mesh, and mononuclear cells were isolated by discontinuous Percoll gradient centrifugation as described above. Purified cells were $>98 \%$ viable as judged by the exclusion of trypan blue. Final T cell numbers were calculated from the total cell yield determined by light microscopy, corrected for the proportion of gated cells that were $\mathrm{CD} 3+$ as determined by flow cytometry, as we have described previously (26). Cell suspensions from the spleen were prepared after mechanical disruption of the capsule between frosted glass slides. Red blood cells were eliminated from the splenocytes using hypotonic lysis, and the resultant cell suspensions were filtered through stainless steel mesh.

Antibody staining and flow cytometric analysis of lymphocyte populations. After purification of $\mathrm{T}$ cell populations from mice, cells were suspended at a concentration of at least $1 \times$ $10^{5}$ cells $/ \mathrm{mL}$ in PBS staining buffer containing $2 \% \mathrm{FCS}$ (vol/ $\mathrm{vol})$ and $0.1 \% \mathrm{NaN}_{3}(\mathrm{wt} / \mathrm{vol})$. Pretitered $\mathrm{MAb}$ directly conjugated to FITC; PE, or biotin were added to cell suspensions at $4^{\circ} \mathrm{C}$ and incubated for $20-30 \mathrm{~min}$. All directly conjugated (FITC, PE, or biotinylated) MAb to the various surface proteins listed below were purchased from PharMingen (San Diego, CA, U.S.A.), and streptavidin Tricolor was purchased from CalTag (South San Francisco, CA, U.S.A.). The MAb used for these studies included anti-CD2 (RM2-5), anti-CD3 $\varepsilon$ (145-2C11), anti-CD4 (GK1.5), anti-CD8 $\alpha$ (53-6.7), antiCD8 $\beta$ (53-5.8), anti-L-selectin (CD62L; MEL-14), anti-CD69 (H1.2F3), anti-TCR $\beta$ (H57-597), and anti-TCR $\gamma \delta$ (GL-3). Cells were incubated in antibody staining buffer on ice for 20 min with the primary MAb, washed twice, and then incubated with the secondary reagent for an additional $20 \mathrm{~min}$. At the completion of the staining reactions, cells were washed as above and resuspended in fixative [PBS staining buffer with $1 \%$ (wt/vol) paraformaldehyde] until analysis by flow cytometry. 
The samples were run on a FACScan flow cytometer (Becton-Dickinson Immunocytometry Systems, San Jose, CA, U.S.A.), equipped with a $15-\mathrm{mW}$ nm air-cooled argon-ion laser in the UCLA or the University of Virginia Flow Cytometry Core Facility. Between 1,500 and 10,000 gated events, based on the forward light scatter and side light scatter properties of the cell preparations, were acquired using C30/FACScan Research or CELLQuest software (Becton-Dickinson). Single and multiple parameter analysis using dot plots and histograms with corresponding statistics were used.

Histologic and immunocytochemical studies. Segments of small and large intestine were excised and cleaned as described in the previous section. The intestine was immersed en bloc in Optimal Cutting Temperature (OCT) Compound (Miles Inc., Elkhart, IN, U.S.A.) and frozen on dry ice. Frozen sections were cut at $5 \mu \mathrm{m}$ on a cryostat microtome and placed on coated glass slides. These sections were air dried, fixed in acetone, and stored at $-80^{\circ} \mathrm{C}$ until use. Frozen tissue sections were hydrated with PBS and then blocked with 20\% normal serum (Vector Laboratories Inc., Burlingame, CA, U.S.A.) in PBS for $20 \mathrm{~min}$. Sections were incubated with pretitered $\mathrm{MAb}$ specific for anti-CD $3 \varepsilon$ in PBS supplemented with $2 \% \mathrm{FCS}$ for $60 \mathrm{~min}$ at $4^{\circ} \mathrm{C}$. The sections were then rinsed in PBS and incubated with biotinylated goat anti-hamster (Vector Laboratories) for $30 \mathrm{~min}$ at $4{ }^{\circ} \mathrm{C}$. After incubation, tissue samples were washed and incubated with avidin-horseradish peroxidase, and then positively staining cells were visualized with 3-amino-9ethylcarbazole as described by the manufacturer (Vecastain Elite, Vector Laboratories). Control sections were prepared using hamster IgG group $1 \kappa(\mathrm{A} 19-3)$ isotype control MAb or after addition of biotinylated $\mathrm{MAb}$ conjugate alone. Before microscopic analysis, all tissue sections were counterstained with hematoxylin blue (Biomeda, Foster City, CA, U.S.A.). Stained tissue sections were photographed through an Olympus microscope with an attached camera.

\section{RESULTS}

$A$ dramatic increase in CD3+ IEL occurs between ages 2 and $4 \boldsymbol{w} \boldsymbol{k}$. We analyzed the number of the T cells obtained from the intestine in the weeks after birth. Quantitation of $\mathrm{T}$ cell numbers within the epithelial compartments revealed a parallel increase in the number of $\mathrm{T}$ cells in both the large and small intestine, with numerically the most dramatic increase occurring between 2 and 4 wk postnatal age (Fig. 1). SI-IEL increased on average 100-fold from 2 to $4 \mathrm{wk}$ postnatal age, with a 10 -fold increase occurring in each weekly interval. The large intestine exhibited a similar increase in $\mathrm{T}$ cell number from 2 to $4 \mathrm{wk}$, increasing on average 58-fold (Fig. 1). Beyond 4 wk postnatal age, the number of T cells within the epithelium increased on average 2-fold among SI-IEL to reach the adult level. In the large intestine, numbers of IEL equivalent to the adult level were reached earlier, by 4 wk of age (Fig. 1). The marked increase in $\mathrm{T}$ cell numbers from 2 to $4 \mathrm{wk}$ is specific to the intestinal epithelial compartment, as $\mathrm{T}$ cells within the lamina propria increased by nearly 6 -fold in the small intestine and 3-fold in the large intestine, and were only slightly increased in the spleen (data not shown). These results indicate

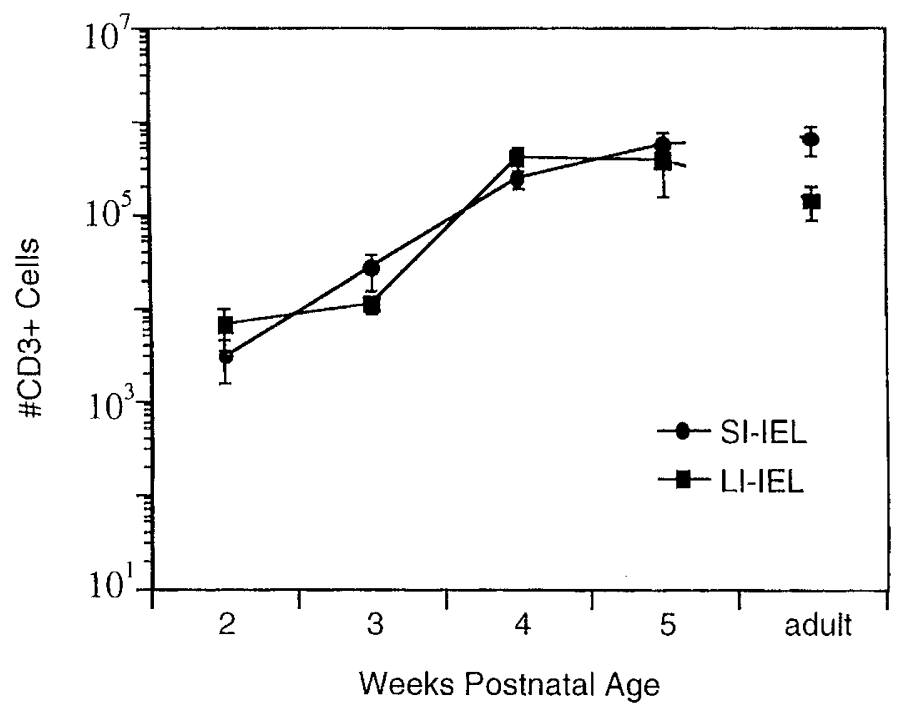

Figure 1. CD3 + T cell expansion in the intestinal epithelium during postnatal development in mice. Mononuclear cells were prepared at weekly intervals from the epithelium of the large and small intestine as described in Methods. Data are expressed as the logarithmic number of CD3 + cells calculated from the total cell yield (either from the entire small intestine, pylorus to cecum, or large intestine, cecum to rectal folds) by light microscopy, corrected for the percentage of CD3 + cells as determined by flow cytometric analysis of gated cell populations stained with an anti-CD3 MAb. Each data point corresponds to the mean of two to four experiments. Error bars correspond to SEM.

that significant $\mathrm{T}$ cell accumulation or expansion occurs within the intestinal epithelium during the early weeks of postnatal life.

T cell colonization parallels the morphologic development of the intestinal mucosa. It remained possible that the number of IEL isolated from mice in the early postnatal period was influenced by differences in the properties of intestinal mucus, the integrity of the epithelial layer, or differences in lymphocyte size and density, rather than the absolute number of IEL. This prompted us to examine thin sections of the large and small intestine at different stages of development by immunohistochemical analysis for CD3 + cells. The mucosal surface of the small intestine demonstrated significant growth in parallel with the increasing number of $\mathrm{T}$ cells that were isolated from the intestinal epithelium, particularly between 1 to $3 \mathrm{wk}$ of postnatal age. At $1 \mathrm{wk}$ of age, few CD3 $+\mathrm{T}$ cells were present within the small intestine whereas many $\mathrm{CD} 3+\mathrm{T}$ cells were seen at $3 \mathrm{wk}$ of age (Fig. 2, $A$ and $B$ ). Additionally, the intestinal villi were shorter and less developed when compared with the intestine at $3 \mathrm{wk}$ of postnatal age (Fig. 2, $A$ and $B$ ). At 1 wk of age, fewer than $10 \%$ of high-power fields examined had 1-2 CD3 + cells, with the majority of T cells located in the lamina propria compared with the epithelium (Fig. $2 A$ and data not shown). A dramatic increase in CD3 $+\mathrm{T}$ cells in the small intestine was, however, apparent in the epithelium at $3 \mathrm{wk}$ of age and in adult mice (Fig. 2, $B$ and $C$ ). Maturational changes were also evident in the large intestine, although during the same period, these changes were less dramatic than those seen in the small intestine. The mucosal surface of the large intestine at 1 wk of age had fewer $T$ cells than were present in the lamina propria or epithelium of the large intestine at $3 \mathrm{wk}$ of 
age or in adult mice (Fig. 2, $D-F$ ). Although approximately 5\% of high-power fields contained 3-4 CD3 $+\mathrm{T}$ cells in the epithelium at $1 \mathrm{wk}$ of age, nearly every high-power field at 3 wk of age and in adult mice contained 3-4 CD3 + IEL (Fig. 2, $D-F)$. These data demonstrate that increases in CD3+ T cells are coupled with growth and development in the mucosal surface of the intestine during neonatal life and that these changes are more dramatic in the small intestine than in the large intestine.

TCR $\alpha \beta+I E L$ are enriched in the intestine before TCR $\boldsymbol{\gamma} \boldsymbol{\delta}+\boldsymbol{I E} \boldsymbol{L}$. The early appearance of TCR $\gamma \delta+\mathrm{T}$ cells during thymocyte ontogeny in the mouse led us to ask whether $\gamma \delta+$ $\mathrm{T}$ cells were present in the intestinal epithelium before or coincident with TCR $\alpha \beta+$ IEL $(27,28)$. IEL were prepared from the intestinal epithelium beginning at $2 \mathrm{wk}$ of age, and TCR $\alpha \beta+$ and TCR $\gamma \delta+$ cells were identified by staining with MAb specific for each TCR isotype. A representative twocolor flow cytometry dot plot showing the proportion of cells expressing either TCR isotype in the total lymphocyte gate among IEL and splenocytes at 2 and 3 wk of postnatal age is shown in Figure 3. The majority of T cells at $2 \mathrm{wk}$ of age in all sites expressed the TCR $\alpha \beta$ (Fig. 4). However, at 3 wk of age, the percentage of TCR $\gamma \delta+$ IEL was enriched 4.4-fold in the small intestine, increasing from 6 to $29 \%$, whereas T cells were enriched 1.8-fold in the large intestine and 1.4-fold in the spleen (Fig. 3). Furthermore, the increase in TCR $\gamma \delta+$ IEL was coincident with a decrease in gated mononuclear cells that did not express either TCR isotype (Fig. 3). As the majority of TCR-negative cells within the IEL lymphocyte gate express the hematopoietic lineage marker CD45, TCR - CD45+ cells may represent precursors of TCR $\gamma \delta+$ IEL, which may complete their development in situ to become mature IEL (data not shown). By contrast with the epithelium, only a small proportion of $\mathrm{T}$ cells in the lamina propria of either the small or large intestine expressed the TCR $\gamma \delta+$ (Fig. 3 and data not shown).

A proportional representation of TCR isotype usage among CD3 + IEL in the large and small intestine, as opposed to the previous analysis based on the proportion of $\mathrm{T}$ cells expressing
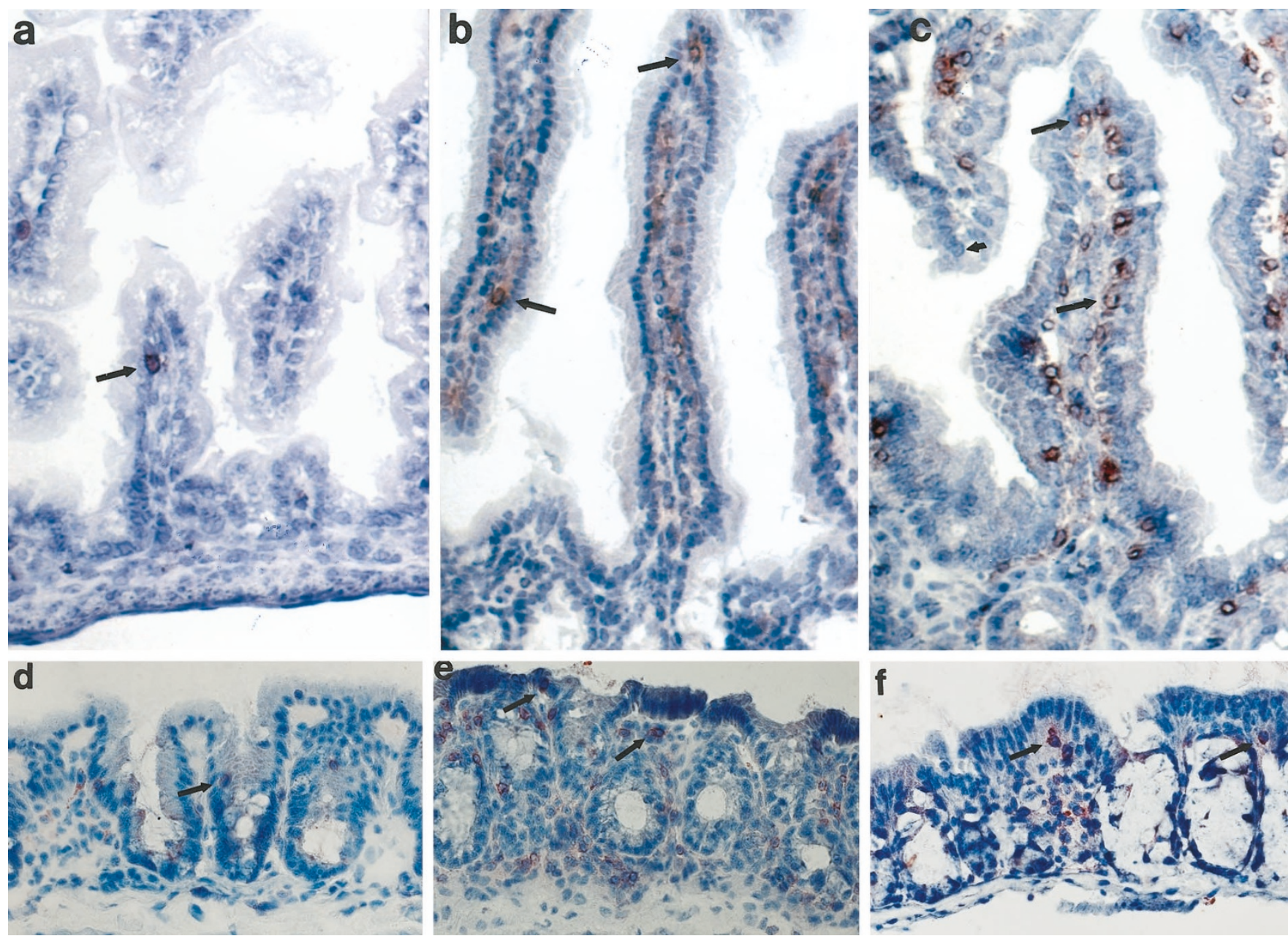

Figure 2. Anatomic distribution of $\mathrm{CD} 3+$ cells in the epithelium of the intestine during development. The small and large intestines were harvested from mice at 1,3 , and 12 wk of postnatal age and embedded in OCT medium. Frozen sections of 5- $\mu \mathrm{m}$ thickness were incubated with anti-CD3 MAb followed by biotinylated goat anti-hamster Ig. CD3 + cells were identified after incubation with avidin-biotin complex and visualized (red) with 3-amino-9-ethylcarbazole substrate as per the manufacturer (Vector Laboratories). A, the small intestine at 1 wk shows short villi and few CD3+ IEL (arrow). The small intestine at 3 $(B)$ and $12 \mathrm{wk}(C)$ shows longer villi with notably increased CD3 + IEL (arrows). D, the large intestine at 1 wk of life shows few mucosal crypts with CD3+ IEL. The large intestine at $3(E)$ and at $12 \mathrm{wk}(F)$ of life shows increased density of mucosal crypts and more abundant CD3+ IEL (arrows). Slides were counterstained with hematoxylin and shown at $\times 500$ original magnification. Representative sections after examination of the entire intestine of at least three individual mice are shown. 


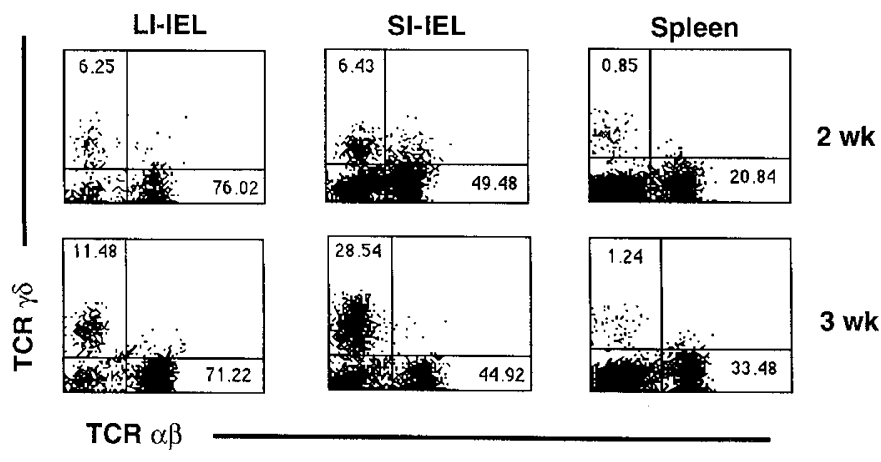

Figure 3. TCR isotype expression by IEL during development. IEL prepared from the large and small intestines of mice at 2 and $3 \mathrm{wk}$ of age were stained with directly conjugated anti-TCR $\alpha \beta$-FITC and anti-TCR $\gamma \delta$-PE. Representative two-color immunofluorescence analyses of LI-IEL (left), SI-IEL (middle), and spleen (right) at $2 \mathrm{wk}$ (upper) and $3 \mathrm{wk}$ (lower) are shown. The numbers in the quadrants are the percent of positively staining cells among mononuclear cells gated by forward and side scatter parameters as described in Methods. The quadrants were determined after analysis with isotype control MAb (data not shown). These data are representative of a minimum of seven individual experiments for both the large and small intestine and spleen, and each experiment used pooled samples from at least two mice.

either TCR isotype relative to TCR-negative mononuclear cells in the lymphocyte gate, is shown in Figure 4. This analysis emphasizes the regional differences and dynamic changes we demonstrated for establishment of CD3 + IEL during development (Fig. 2). An average of $84 \%$ (minimum $75 \%$, maximum $95 \%$ ) of SI-IEL isolated at $2 \mathrm{wk}$ of postnatal age were TCR $\alpha \beta+$ T cells (Fig. 4). Beginning at 3 wk of age and through to adulthood, however, there were nearly equal proportions of TCR $\alpha \beta+$ and TCR $\gamma \delta+$ SI-IEL (Fig. 4). The relative proportions of TCR $\alpha \beta+$ and $\gamma \delta+$ LI-IEL isolated during these same intervals were similar to those found in adult mice and show a consistent majority of TCR $\alpha \beta+$ cells (mean, 83-93\%) compared with a lesser percentage of $\gamma \delta+\mathrm{T}$ cells (mean, $7-17 \%$; Fig. 4B). These results demonstrate that the majority of $\mathrm{T}$ cells within the epithelium of both the large and small intestine at $2 \mathrm{wk}$ postnatal age are TCR $\alpha \beta+\mathrm{T}$ cells, with selective enrichment of TCR $\gamma \delta+$ T cells occurring within the small intestinal epithelium at $3 \mathrm{wk}$ of postnatal age. Therefore, unlike the thymus, the epithelium of the small and large intestine is colonized with TCR $\alpha \beta+$ T cells first $(27,28)$.

CD4+ and CD8+ expression by IEL varies during postnatal life. To determine whether IEL present in early neonatal life had an unusual pattern of coreceptor expression when compared with adult mice, we examined IEL for expression of CD4 and CD8. SI-IEL at 2 wk of age were composed of nearly equal proportions of CD4 and CD $8 \alpha \beta+$ single-positive T cells with a ratio of $\mathrm{CD} 4+$ to $\mathrm{CD} 8 \alpha \beta+$ T cells of $1: 1$ (Table 1). The analysis of $\mathrm{CD} 8 \alpha \beta+\mathrm{T}$ cells excludes the largely $\mathrm{CD} 8 \alpha \alpha+$, TCR $\gamma \delta+$ population as well as TCR $\alpha \beta+$, CD $8 \alpha \alpha+$ IEL. Beginning at 3 wk of age and in adult mice, SI-IEL were enriched for CD8 $+\mathrm{T}$ cells with a decrease in the CD4:CD8 ratio to a low of 0.5:1 (Table 1). $\mathrm{CD} 4+, \mathrm{CD} 8 \alpha \alpha+$ doublepositive cells, although present, did not account for a significant proportion of SI-IEL in the weeks after birth, suggesting that accumulation of double-positive cells is not required for the development of CD4+ or CD8+ IEL (Fig. 5A). Further- more, whereas only $28 \%$ of $\mathrm{T}$ cells on average expressed the $\mathrm{CD} 8 \alpha \alpha$ homodimer at $2 \mathrm{wk}$ of age, this increased to adult proportions at $3 \mathrm{wk}$ of age, when $71 \%$ of CD8 + IEL expressed CD $8 \alpha \alpha$ (Table 1). In the example shown in Figure $5 B, 34 \%$ of mononuclear cells prepared from the small intestine are $\mathrm{CD} 8 \alpha \alpha+$, or when expressed as a proportion of the total CD $8+\mathrm{T}$ cells, $81 \%$ of IEL at $3 \mathrm{wk}$ expressed CD $8 \alpha \alpha$ (Fig. $5 \mathrm{~A}$ and Table 1). By contrast, only $19 \%$ of IEL at this time interval expressed $\mathrm{CD} 8 \alpha \beta$ (Fig. $5 B$ and Table 1). The increase in CD8 $\alpha \alpha+$ IEL from 2 to 3 wk of age correlated with the expansion of TCR $\gamma \delta+$ IEL and a decrease in CD4-CD8double-negative cells from $34 \%$ at 2 wk of age to $15 \%$ of $\mathrm{T}$ cells at 3 wk of age (Figs. 3 and 4 and Table 1).

By contrast to the changes that occurred among SI-IEL during ontogeny, the majority of LI-IEL were CD4 singlepositive $\mathrm{T}$ cells throughout the ages examined (Fig. $5 \mathrm{~A}$ and Table 1). The ratio of CD4+ to CD8+ T cells in the large intestine was more similar to SI-IEL analyzed at the earliest times during ontogeny with a ratio of 2:1 at $2 \mathrm{wk}$ of age (Table 1). This ratio increased to $3: 1$ by $3 \mathrm{wk}$ of age and remained in

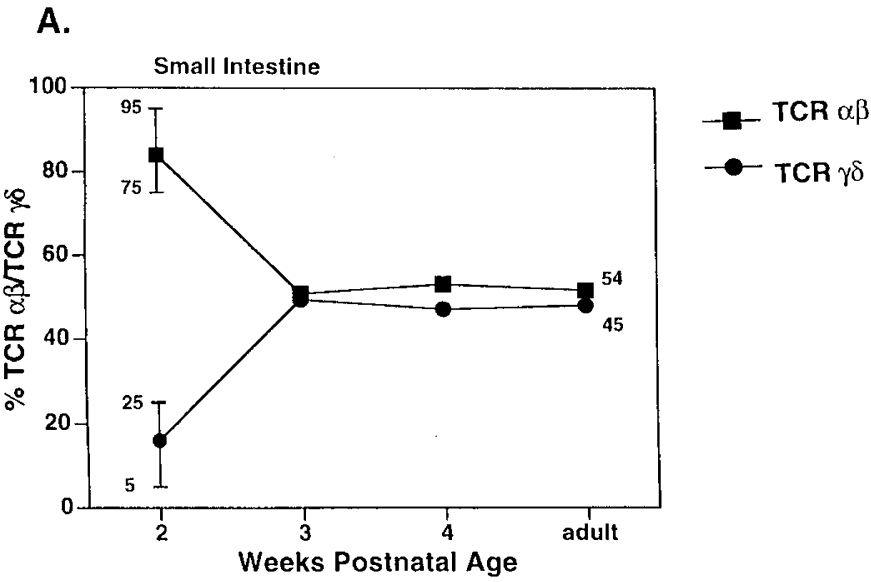

B.

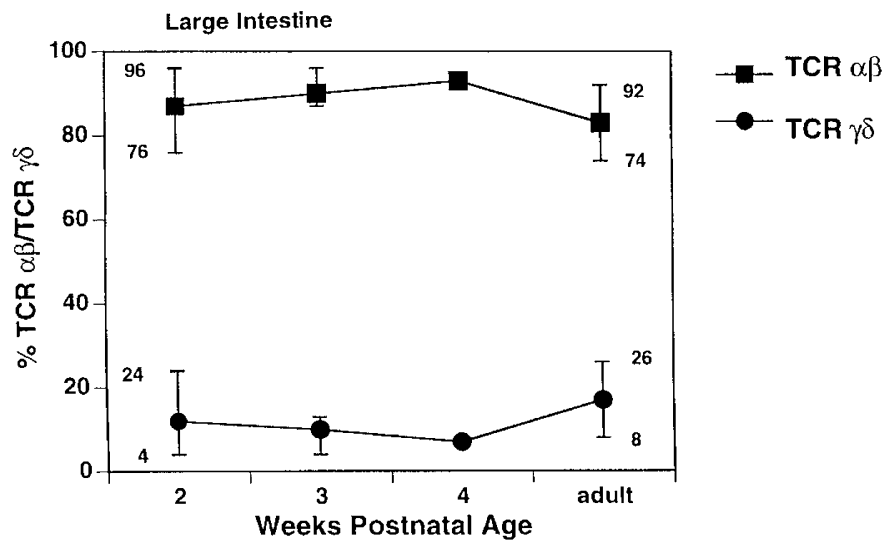

Figure 4. TCR usage among populations of IEL during postnatal development in mice. The percent of TCR $\alpha \beta+$ cells $(\square)$ and TCR $\gamma \delta+$ cells ( ) among IEL in the small intestine $(A)$ and large intestine $(B)$ are plotted as a proportion of the total TCR + cells present at weekly intervals from 2 to $4 \mathrm{wk}$ and in adult mice between 5 and 12 wk of age. Each point corresponds to the mean of data generated from a minimum of five experiments derived from pools consisting of at least two mice per pool. The bars depict the minimum and maximum values obtained across the experimental series. 
Table 1. CD4 and CD8 coreceptor expression among populations of IEL during postnatal development

\begin{tabular}{lccc}
\hline $\begin{array}{c}\text { Postnatal age } \\
(\text { wk })\end{array}$ & $\begin{array}{c}\mathrm{CD} 8 \alpha \alpha / \mathrm{CD} 8_{\mathrm{T}}{ }^{*} \\
(\%+)\end{array}$ & $\begin{array}{c}\mathrm{CD} 4: \mathrm{CD} 8 \alpha \beta \\
\text { Small intestine } \\
2\end{array}$ & $\begin{array}{c}\mathrm{CD} 4, \mathrm{CD} 8- \\
(\%+)\end{array}$ \\
\hline 3 & $28 \pm 4$ & $1: 1$ & $34 \pm 4$ \\
$5-12$ & $71 \pm 5$ & $1.1: 1$ & $15 \pm 5$ \\
Large intestine & $76 \pm 10$ & $0.5: 1$ & $11 \pm 3$ \\
2 & $55 \pm 6$ & $1.9: 1$ & $17 \pm 2$ \\
3 & $59 \pm 6$ & $3.1: 1$ & $19 \pm 5$ \\
$5-12$ & $59 \pm 8$ & $3.1: 1$ & $22 \pm 1$ \\
\hline
\end{tabular}

The expression of $\mathrm{CD} 4, \mathrm{CD} 8 \alpha, \mathrm{CD} 8 \beta$, and $\mathrm{CD} 3$ was determined by threeand four-color immunofluorescence analysis of IEL, or deduced from two- and three-color analysis done separately on IEL prepared at weekly intervals at 2 and $3 \mathrm{wk}$ and then between 5 and $12 \mathrm{wk}$. $*$ The percent of CD8 $\alpha \alpha+$ IEL is expressed as the percent of the total $\mathrm{CD} 3+\mathrm{CD} 8+\mathrm{T}$ cells $\left(\mathrm{CD} 8_{\mathrm{T}}\right)$, determined from the sum of the percent of $\mathrm{CD} 8 \alpha \beta+$ and $\mathrm{CD} 8 \alpha \alpha+\mathrm{T}$ cells. The ratio of $\mathrm{CD} 4$ to $\mathrm{CD} 8$ is the ratio to $\mathrm{CD} 4+$ to $\mathrm{CD} 8 \alpha \beta+\mathrm{T}$ cells. (Double-positive cells were $2-6 \%$ of the total in the small intestine and $1-2 \%$ in the large intestine and were excluded from the analysis.) The percent of CD4-, CD8- doublenegative cells is presented as a proportion of the total CD3 + cells. The results are summarized from two to four experiments at each time point, and each experiment is based on a pool of cells derived from at least two mice. All results are presented as mean $\pm \mathrm{SD}$.

this range to adulthood (Fig. $5 A$ and Table 1). Therefore, LI-IEL are enriched in CD4 + T cells early in neonatal life and in adulthood to a greater extent than what we observed at any time in the small intestine (Fig. $5 A$ and Table 1). The majority of $\mathrm{T}$ cells in the lamina propria of the large and small intestine throughout neonatal life and in adult mice were CD4+ and $\mathrm{CD} 8 \alpha \beta+$, with few to no CD8 $\alpha \alpha+\mathrm{T}$ cells (data not shown). Therefore, unlike SI-IEL, LPL T cells were more similar to LI-IEL and to $\mathrm{T}$ cells in the spleen during this time (Fig. 5A).

Neonatal IEL express a distinct cell surface phenotype from adult IEL. Populations of IEL express a unique cell surface phenotype when compared with $\mathrm{T}$ cells found in nonmucosal sites in the periphery. For example, a large proportion of SI-IEL isolated from adult mice express the early activation antigen, CD69, with low levels of expression of the lymph node homing receptor, CD62L, and the coactivation antigen, $\mathrm{CD} 2(6,7)$. An overlapping, although smaller, subset of LI-IEL in adult mice also express CD69, but by contrast to SI-IEL, a greater proportion of LI-IEL in adult mice express $\mathrm{CD} 2$ and $\mathrm{CD} 62 \mathrm{~L}(6,7)$. To determine whether IEL during postnatal development exhibited an adult pattern of expression for these antigens, we examined CD3 + IEL during ontogeny for the expression of CD69, CD62L, and CD2. Figure 6 is a representative histogram demonstrating CD69 expression by TCR $\alpha \beta+$ and TCR $\gamma \delta+$ IEL in mice at 2, 3, and $8 \mathrm{wk}$ of postnatal age. The results show that the proportion of CD69+ $\mathrm{T}$ cells increased with age in all populations, although TCR $\gamma \delta+$ IEL in both the large and small intestine exhibited a more rapid kinetics of CD69 acquisition and a more uniform distribution within the population than did TCR $\alpha \beta+$ IEL (Fig. 6). The data also show that a greater percentage of TCR $\alpha \beta+$ cells within the small intestine expressed CD69 than do LI-IEL at all times during ontogeny (Fig. 6). Furthermore, when CD3 + IEL were examined for the expression of CD62L, a marker of resting and naïve $\mathrm{T}$ cells, a greater proportion of SI-IEL on average expressed this antigen at 2 wk of life (39\%) than at later times in ontogeny and in adulthood (2\%) (Table 2). By contrast, $70 \%$ of LI-IEL at 2 wk expressed CD62L, which decreased to $27 \%$ in the adult (Table 2). A similar decrease in CD2 expression by SI-IEL compared with LI-IEL was also seen. Although $79 \%$ of SI-IEL were positive for CD2 at $2 \mathrm{wk}$ of life, this decreased to only $8 \%$ among adult SI-IEL, whereas LI-IEL expressed high levels of CD2 throughout life (Table 2). These data are consistent with the presence of more activated and specialized $\mathrm{T}$ cells in the small intestine as development proceeds. These data demonstrate that early TCR $\alpha \beta+$ IEL may be immature or resting $\mathrm{T}$ cells and that the changing luminal environment or the colonization of the epithelium by TCR $\gamma \delta+$ IEL in response to suckling and then weaning may shape the phenotype of subsequent TCR $\alpha \beta+\mathrm{T}$ cells within the intestinal epithelium.

\section{DISCUSSION}

We have analyzed ontogeny of intestinal mucosal $\mathrm{T}$ cells in the large and small intestine of neonatal mice. The phenotypic differences between IEL in the large and small intestine of adult mice prompted us to examine the parallel establishment of these populations during neonatal life $(6,10-12)$. In agreement with previous reports that examined the small intestine of the rat and mouse, we found that IEL arise in the small intestine after birth (14-16, 18-21). We also found that IEL develop in the large intestine with a similar kinetics. We found, however, that the cell surface phenotype of IEL in the large and small intestine of neonatal mice were similar only up until the time of weaning, after which time they diverged and acquired the characteristics of IEL found in adult mice at each location $(6,10-12)$. For example, from 2 wk of postnatal age and through to adulthood, the majority of LI-IEL, like T cells found in the lamina propria and spleen, were $\mathrm{CD} 2+$, TCR $\alpha \beta+$ and were either $\mathrm{CD} 4+$ or $\mathrm{CD} 8 \alpha \beta+$ single-positive $\mathrm{T}$ cells. This $\mathrm{T}$ cell population was also found among the majority of SI-IEL at 2 wk of age, after which time TCR $\gamma \delta+$ and TCR $\alpha \beta+$ T cells expressing CD $8 \alpha \alpha+$ were significantly increased among SIIEL. Our data suggest that intestinal T cells may be functionally more similar to $\mathrm{T}$ cells found in nonmucosal sites in the periphery in early postnatal life and that the maturation of intestinal $\mathrm{T}$ cells is induced by changes that occur during weaning.

The analysis of mucosal $\mathrm{T}$ cells in suspension by flow cytometry and in situ by immunohistology were both consistent in demonstrating that few CD3 + IEL were present in either the large or small intestine at $1 \mathrm{wk}$ of age. When we examined frozen sections after the preparation of IEL beginning at 2 wk of age, we confirmed that the lamina propria remained intact, suggesting that epithelial $\mathrm{T}$ cell preparations were not contaminated with lamina propria $\mathrm{T}$ cells (data not shown). Furthermore, immunohistology demonstrated that the increased density of IEL and the marked expansion of the villus epithelium contributed to the increased number of IEL isolated from the small intestine during later times in postnatal life. By contrast, the increased number of IEL isolated from the 


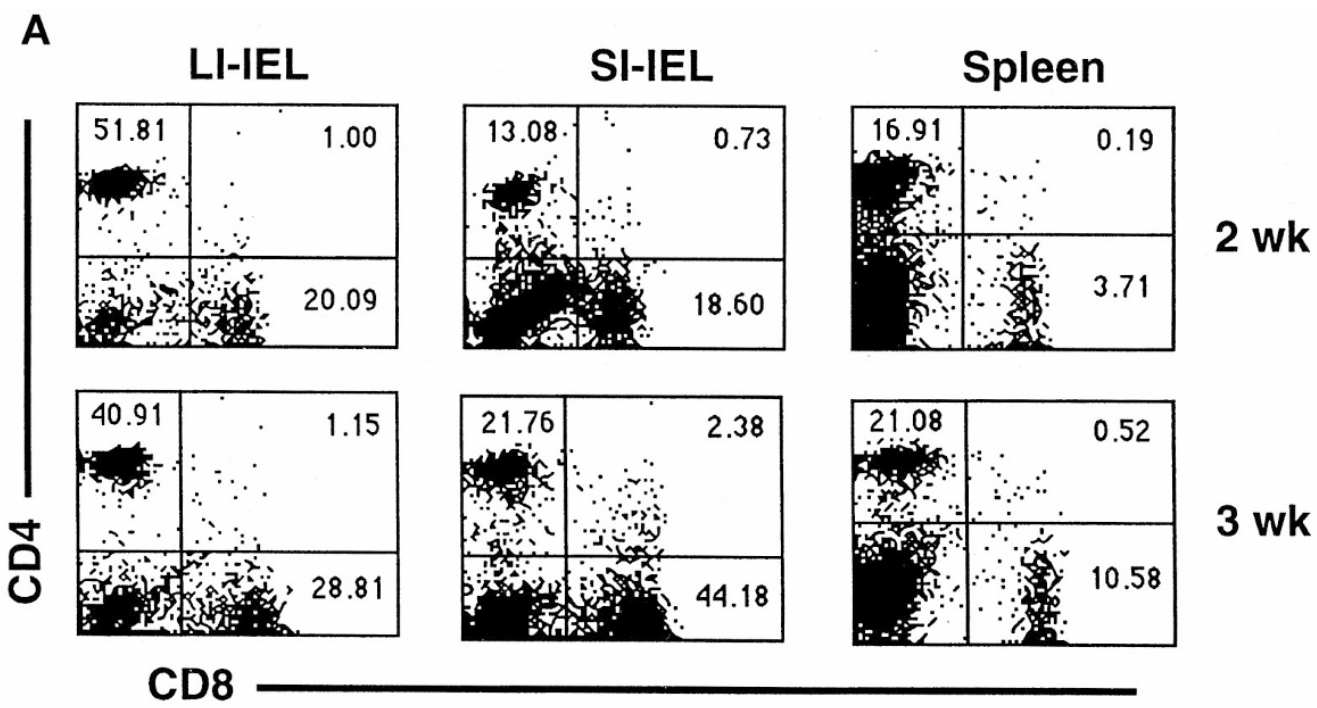

B

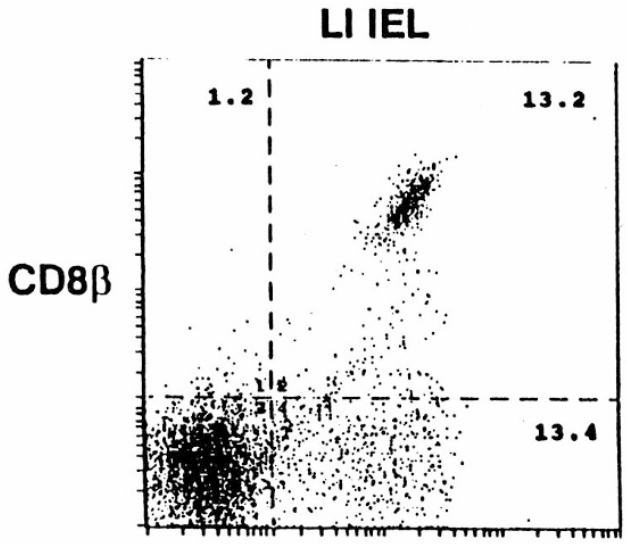

CD8 $\alpha$

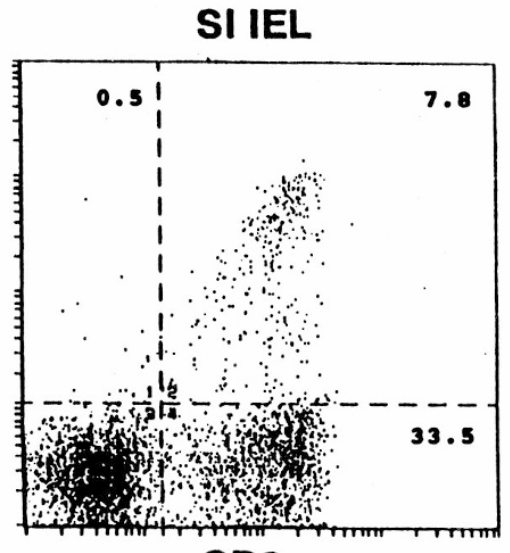

Figure 5. CD4 and CD8 coreceptor expression by IEL during early postnatal life. A, cells isolated from LI-IEL (left), SI-IEL (middle), and spleen (right) at 2 and 3 wk of age were stained with anti-CD4 and anti-CD8 $\alpha$. The numbers in the quadrants are the percent positively staining cells at 2 and 3 wk of age. $B$, LI-IEL and SI-IEL at $3 \mathrm{wk}$ of age were stained with anti-CD $8 \alpha$ and anti-CD $8 \beta$, and a two-color immunofluorescence dot plot is shown. LI-IEL, SI-IEL, and splenocytes were prepared in parallel from the same pool of mice in each case. The percentages refer to the fraction of total gated cells staining positive for each antigen. Quadrants were determined after staining with unconjugated isotype control MAb. These results are representative of six individual experiments, with data derived from pools of at least three mice in all cases.

large intestine was largely related to an increased density of IEL per unit length of the gut. The small number of IEL present at birth in the neonatal mouse stands in sharp contrast to the ontogeny of mucosal $\mathrm{T}$ cells in other vertebrates. For example, IEL are readily detectable by $11 \mathrm{wk}$ gestation in humans and are also present in large numbers before hatching in chickens (29-31). These data suggest that maturation of the intestine may be accelerated in other vertebrates when compared with the mouse.

The factors that drive $\mathrm{T}$ cell colonization of the intestine in the weeks after birth are not well understood. It is likely that systemic and intestinal factors, such as changes in hormones, the absence of suckling, exposure to food antigens, or changes in the bacterial flora, occur with weaning and are responsible for the changes that occur among IEL during postnatal life. When fetal intestine is placed under the kidney capsule, the total number of IEL is reduced in the intestinal graft when compared with the normally sited intestine, suggesting that luminal contents are important in the development of a normal complement of IEL (23). Furthermore, when mature TCR $\alpha \beta+, \mathrm{CD} 4+$ or $\mathrm{CD} 8 \alpha \beta+\mathrm{T}$ cells prepared from peripheral lymph nodes are transferred to severe combined immunodeficient mice, the large intestine is colonized by $\mathrm{T}$ cells earlier than the small intestine (26). Additionally, maximal expansion of IEL in both the large and small intestine is dependent on normal microbial flora as the number of engrafted $\mathrm{T}$ cells is reduced when $\mathrm{T}$ cells are transferred to severe combined immunodeficient mice with restricted flora and housed under germ-free conditions (26). Likewise, TCR $\alpha \beta+$ IEL are reduced in germ-free mice and increase with transfer to conventional conditions whereas the number of TCR $\gamma \delta+$ IEL are largely unaffected by the germ-free conditions (32). These data strongly suggest that changes in the luminal contents of the intestine during postnatal life vary and contribute to the changes we observed among the $\mathrm{T}$ cells resident within the compartments of the intestine. 


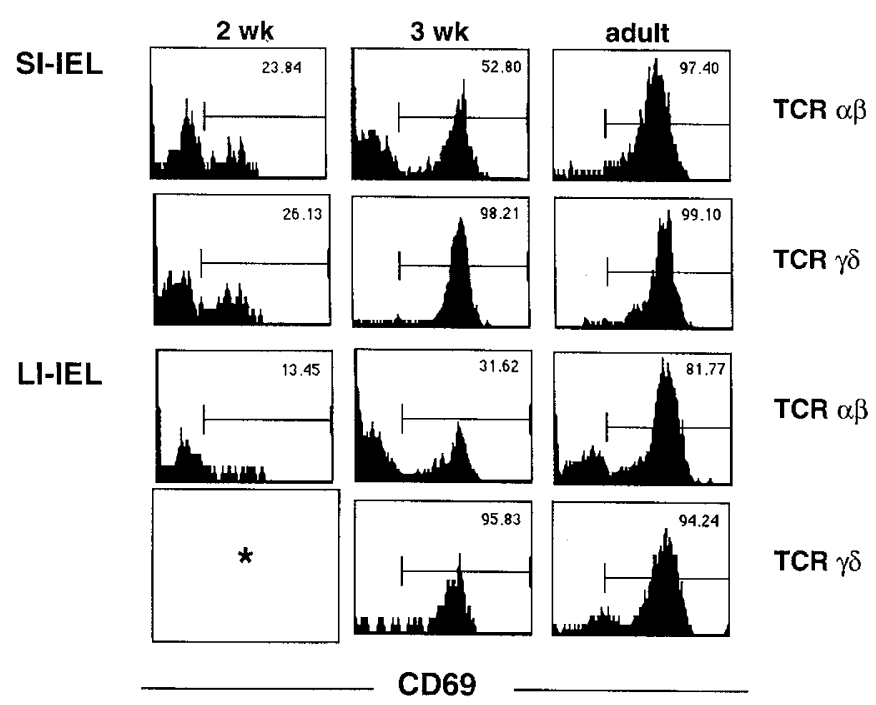

Figure 6. Increased expression of CD69 in mucosal $\mathrm{T}$ cells during postnatal development. SI-IEL and LI-IEL were isolated at 2 and $3 \mathrm{wk}$ and from 8 -wk-old adult mice and prepared for three-color immunofluorescence staining with anti-TCR $\beta$, anti-TCR $\gamma \delta$, and anti-CD69. Cells gated by forward and side light scatter during acquisition were analyzed for the expression of CD69 among cells gated during analysis for TCR $\alpha \beta$ or TCR $\gamma \delta$ expression. Data are expressed as single histograms with CD69 expression on a logarithmic scale. The vertical line denotes background fluorescence after staining with isotype control MAb. The numbers in the histograms represent the percent of positive cells. These data are representative of a minimum of $>10$ experiments derived from pools of at least four mice in the small intestine and four experiments in the large intestine. * too few cells to plot.

The enrichment of TCR $\gamma \delta+, \operatorname{CD} 8 \alpha \alpha+$ T cells that occurs in the small intestinal epithelium that we and others have observed at or about the time of weaning is noteworthy, although the factors responsible for this are as yet unknown (14-16, 18-21). Although TCR $\alpha \beta+$ IEL numbers are markedly low in germ-free mice and increase on transfer to conventional conditions, the number of TCR $\gamma \delta+$ cells is largely unaffected by the germ-free state, suggesting that bacterial flora are less important for the enrichment of these $\mathrm{T}$ cells in the gut $(32,33)$. TCR $\gamma \delta+$ IEL in antigen-minimized and germ-free conditions have reduced cytolytic activity, however, suggesting that environmental antigens may be important in the functional differentiation of this population of IEL (34). The coincident expansion of TCR $\gamma \delta+$ IEL in the small intestine and the maturation and differentiation of the intestinal epithelium that occur at the time of weaning suggest that these events may be linked (22). In fact, TCR $\delta$ knockout mice demonstrate reduced intestinal epithelial and crypt cell turnover and have reduced expression of major histocompatibility complex class II molecules on small intestinal epithelial cells relative to wild-type mice (35). These data are consistent with the notion that TCR $\gamma \delta+$ IEL are important in the normal maturation and development of the intestinal epithelium, perhaps through the secretion of keratinocyte growth factor by these T cells (35, 36).

Although it is clear that a subset of IEL are derived from the thymus and undergo postthymic differentiation in response to antigens encountered in the gut, a subset of IEL in both the large and small intestine may, to some degree, be thymus
Table 2. The expression of activation and adhesion proteins on CD3 + intestinal IEL during postnatal development.

\begin{tabular}{ccc}
\hline $\begin{array}{c}\text { Postnatal age } \\
(\text { wk })\end{array}$ & $\begin{array}{c}\text { CD62L } \\
(\%+)^{*}\end{array}$ & $\begin{array}{c}\text { CD2 } \\
(\%+)^{*}\end{array}$ \\
\hline Small intestine & $39 \pm 17$ & $79 \pm 2$ \\
$\mathbf{2}$ & $5 \pm 4$ & $40 \pm 6$ \\
$\mathbf{3}$ & $2 \pm 2$ & $8 \pm 3$ \\
$\mathbf{5 - 1 2}$ & $70 \pm 29$ & $84 \dagger$ \\
Large intestine & $72 \pm 9$ & $86 \dagger$ \\
$\mathbf{2}$ & $27 \pm 23$ & $85 \pm 10$ \\
$\mathbf{3}$ & & \\
$\mathbf{5 - 1 2}$ & & \\
\hline
\end{tabular}

The cell surface expression of CD62L, CD2, and CD3 was determined by three-color immunofluorescence analysis of IEL prepared at the weekly intervals shown and from mice between 5 and $12 \mathrm{wk}$ of life, which were pooled. * The percent positive fluorescence of each antigen was determined by flow cytometry as described in the Methods and is shown as the mean \pm SD for $\mathrm{CD} 3+$ cells. The results are summarized from three to 10 experiments at each time point and are derived from pools of at least two mice except where indicated with $\dagger$, where a single experiment derived from at least two mice was performed.

independent $(6,37)$. The presence of TCR $\gamma \delta+, \operatorname{CD} 8 \alpha \alpha+$ single-positive IEL in congenitally athymic nude mice and the development of this IEL subset after bone marrow transfer to thymectomized and irradiated recipients are both consistent with the thymus-independent development of this subset of IEL $(1,6,12,38-41)$. Our results support the notion that most IEL in the small intestine, like the majority of IEL in the large intestine, are thymus dependent in the immediate neonatal period and that $\mathrm{T}$ cells developing through nonthymic pathways may be activated at or about the time of weaning. The enrichment of TCR,- CD45 + cells in the intestinal epithelium before the increase in TCR $\gamma \delta+$ IEL suggests a precursorproduct relationship between these cells (Fig. 3). Further studies to elucidate the lineage relationships between these populations are currently in progress.

In summary, we have demonstrated that $\mathrm{T}$ cells within the large intestinal epithelium and lamina propria are established rapidly in the postnatal period and are phenotypically similar to $\mathrm{T}$ cells in the spleen throughout postnatal ontogeny and into adulthood. By contrast, $\mathrm{T}$ cells within the small intestinal epithelium are similar to $\mathrm{T}$ cells found throughout the gut and spleen up until the time of weaning, after which time T cells unique to the small intestine are present. This suggests that $\mathrm{T}$ cells in the large intestine and lamina propria are less dependent on changes within the intestine that are associated with suckling and weaning, when compared with $\mathrm{T}$ cells within the small intestinal epithelium. The influence of suckling and weaning on IEL in the small intestine may allow coupling of this $\mathrm{T}$ cell population to the maturation of the intestinal epithelium or to the changes in luminal contents that occur during this time. Our data have significant implications for understanding the postnatal maturation of the intestine in the context of the natural progression of luminal microbial flora and the programmed development of the epithelial cells lining the gut. For example, many of these elements may be altered after premature delivery and hospitalization. Alterations in the normal developmental process may have a significant impact on the development of necrotizing enterocolitis in the newborn or 
in the development of other inflammatory, allergic, or cancerous conditions that occur throughout life in children and in adults.

Acknowledgments. The authors thank Dr. Mitchell Kronenberg for advice and careful reading of the manuscript, Katherine Williams (UCLA) and William Ross (University of Virginia) for flow cytometry data acquisition and analysis, Marcia Bentz and Erin Tobias for preparing frozen tissue sections (University of Virginia), and Xiao Ming Wang for technical assistance (University of Virginia).

\section{REFERENCES}

1. Guy-Grand D, Cerf-Bensussan N, Malissen B, Malassis-Seris M, Briottet C, Vassalli P 1991 Two gut intraepithelial CD8 + lymphocyte populations with different T cell receptors: a role for the gut epithelium in T cell differentiation. J Exp Med 173:471481

2. Lefrancois L 1991 Phenotypic complexity of intraepithelial lymphocytes of the small intestine. J Immunol 147:1746-1751

3. Goodman T, Lefrancois L 1988 Expression of the $\gamma--\delta$ T-cell receptor on intestinal CD8 + intraepithelial lymphocytes. Nature 333:855-858

4. Goodman T, Lefrancois L 1989 Intraepithelial lymphocytes: anatomical site, not T cell receptor form, dictates phenotype and function. J Exp Med 170:1569-1581

5. Mosley RL, Styre D, Klein JR 1990 CD4+CD8+ murine intestinal intraepithelial lymphocytes. Int Immunol 2:361-365

6. Camerini V, Panwala C, Kronenberg M 1993 Regional specialization of the mucosa immune system: intraepithelial lymphocytes of the large intestine have a different phenotype and function than those of the small intestine. J Immunol 151:1765-1776

7. Sydora B, Aranda R, Tangri S, Holcombe H, Camerini V, Castano R, Cardell S, Huse W, Peterson P, Cheroutre H, Kronenberg M 1996 Lymphocyte-epithelial cell cross talk in the intestine: do nonclassical class I molecules have a big part in the dialogue? In: Kagnoff M, Kiyono H (eds) Mucosal Immunology. Academic Press, San Diego, CA, pp 205-222

8. Kilshaw PJ, Murant SJ 2071990 A new surface antigen on intraepithelial lymphocytes in the intestine. Eur J Immunol 20:2201-2202

9. Van Houten NP, Mixter F, Wolfe J, Budd RC 1993 CD2 expression on murine intestinal intraepithelial lymphocytes is bimodal and defines proliferative capacity. Int Immunol 5:665-672

10. Lundqvist C, Baranov V, Hammarstrom S, Athlin L, Hammarstrom ML 1995 Intra-epithelial lymphocytes: evidence for regional specialization and extrathymic $\mathrm{T}$ cell maturation in the human gut epithelium. Int Immunol 7:1473-1487

11. Ibraghimov AR, Lynch RG 1994 Heterogeneity and biased T cell receptor $\alpha / \beta$ repertoire of mucosal $\mathrm{CD} 8+$ cells from murine large intestine: implications fo functional state. J Exp Med 180:433-444

12. Boll G, Rudolphi A, Spiess A, Reimann J 1995 Regional specialization of intraepithelial T cells in the murine small and large intestine. Scand J Immunol 41:103-113

13. Boll G, Reimann J 1995 Lamina propria T cell subsets in the small and large intestine of euthymic and athymic mice. Scand J Immunol 42:191-201

14. Steege JC, Buurman WA, Forget PP 1997 The neonatal development of intraepithelial and lamina propria lymphocytes in the murine small intestine. Dev Immunol 5:121128

15. Fichtelius KE, Yunis EJ, Good RA 1968 Occurrence of lymphocytes within the gut epithelium of normal and neonatally thymectomized mice. Proc Soc Exp Biol Med 128:185-188

16. Lyscom N, Brueton MJ 1983 The development of intraepithelial and Peyer's patch lymphocyte sub-types in the small intestine of newborn rats. Clin Exp Immuno $54: 158-162$

17. Lin T, Matsuzaki G, Kenai H, Nomoto K 1994 Progenies of fetal thymocytes are the major source of CD4-CD8 $+\alpha \alpha$ intestinal intraepithelial lymphocytes early in ontogeny. Eur J Immunol 24:1785-1791
18. Bandeira A, Itohara S, Bonneville M, Burlen-Defranoux O, Mota-Santos T, Coutinho A, Tonegawa S 1991 Extrathymic origin of intestinal intraepithelial lymphocytes bearing T-cell antigen receptor gamma delta. Proc Nat Acad Sci USA 88:43-47

19. Herbst JJ, Sunshine P 1969 Postnatal development of the small intestine of the rat. Pediatr Res 3:27-33

20. Al-Nafussi AI, Wright NA 1982 Cell kinetics in the mouse small intestine during immediate postnatal life. Virchows Arch 40:51-62

21. Cummins AG, Steele TW, LaBrooy JT, Shearman DJC 1988 Maturation of the rat small intestine at weaning: changes in epithelial cell kinetics, bacterial flora, and mucosal immune activity. Gut 29:1672-1679

22. Gordon JI, Hermiston ML 1994 Differentiation and self-renewal in the mouse gastrointestinal epithelium. Curr Opin Cell Biol 6:795-803

23. Ferguson A, Parrott DMV 1972 The effect of antigen deprivation on thymusdependent and thymus-independent lymphocytes in the small intestine of the mouse. Clin Exp Immunol 12:477-488

24. Crabbe PA, Nash DR, Bazin H, Eyssen H, Heremans JF 1970 Immunohistochemical observations on lymphoid tissues from conventional and germ-free mice. Lab Invest 22:448-457

25. Davies MDJ, Parrott DMV 1981 Preparation and purification of lymphocytes from the epithelium and lamina propria of murine small intestine. Gut 22:481-488

26. Camerini V, Sydora BC, Aranda R, Nguyen C, MacLean C, McBride WH, Kronenberg M 1998 Generation of intestinal mucosal lymphocytes in SCID mice reconstituted with mature, thymus-derived T cells. J Immunol 160:2608-2618

27. Pardoll DM, Fowlkes BJ, Bluestone JA, Kruisbeek A, Maloy WL, Coligan JE, Schwartz RH 1987 Differential expression of two distinct T-cell receptors during thymocyte development. Nature 326:79-81

28. Wilson AJ, de Villartay P, MacDonald HR 1996 T cell receptor delta gene rearrangement and T early alpha (TEA) expression in immature alpha beta lineage thymocytes: implications for alpha beta/gamma delta lineage commitment. Immunity 4:37-45

29. Spencer J, Dillon SB, Isaacson PG, Macdonald TT 1986 T cell subclasses in fetal human ileum. Clin Exp Immunol 65:553-558

30. Howie D, Spencer J, DeLord D, Pitzalis C, Wathen NC, Dogan A, Akbar A, MacDonald TT 1998 Extrathymic T cell differentiation in the human intestine early in life. J Immunol 161:5862-5872

31. Dunon D, Cooper MD, Imhof BA 1993 Thymic origin of embryonic intestinal gamma/delta T cells. J Exp Med 177:257-263

32. Umesaki Y, Setoyama H, Matsumoto S, Okada Y 1993 Expansion of $\alpha \beta$ T cel receptor-bearing intestinal intraepithelial lymphocytes after microbial colonization in germ-free mice and its independence from thymus. Immunology 79:32-37

33. Bandeira A, Mota-Santos T, Itohara S, Degermann S, Heusser C, Tonegawa S, Coutinho A 1990 Localization of gamma/delta T cells to the intestinal epithelium is independent of normal microbial colonization. J Exp Med 172:239-244

34. Kawaguchi-Miyashita M, Shimizu K, Nanno M, Shimada S, Watanabe T, Koga Y, Matsuoka Y, Ishikawa H, Hashimoto K, Ohwaki M 1996 Development and cytolytic function of intestinal intraepithelial $\mathrm{T}$ lymphocytes in antigen-minimized mice. Immunology 89:268-273

35. Komano H, Fujiura Y, Kawaguchi M, Matsumoto S, Hashimoto Y, Obana S, Mombaerts P, Tonegawa S, Yamamoto H, Itohara S, Nanno M, Ishikawa H 1995 Homeostatic regulation of intestinal epithelia by intraepithelial $\gamma \delta$ T cells. Proc Natl Acad Sci USA 92:6147-615

36. Boismenu R, Havran WL 1994 Modulation of epithelial cell growth by intraepithelial gamma delta $T$ cells. Science 266:1253-1255

37. Kim SK, Reed DS, Heath WR, Carbone F, Lefrancois L 1997 Activation and migration of CD8 T cells in the intestinal mucosa. J Immunol 159:4295-4306

38. Lin T, Matsuzaki G, Kenai H, Nomoto K 1995 Extrathymic and thymic origin of murine IEL: are most IEL in euthymic mice derived from thymus? Immunol Cell Biol 73:469-473

39. Mosley RL, Styre D, Klein JR 1990 Differentiation and functional maturation of bone marrow-derived intestinal epithelial $\mathrm{T}$ cells expressing membrane $\mathrm{T}$ cell receptor in athymic radiation chimeras. J Immunol 145:1369-1375

40. Poussier P, Edouard P, Lee C, Binnie M, Julius M 1992 Thymus-independent development and negative selection of T cells expressing T cell receptor $\alpha / \beta$ in the intestinal epithelium: evidence for distinct circulation patterns of gut- and thymusderived T lymphocytes. J Exp Med 176:187-199

41. Rocha B, Vassalli P, Guy-Grand D 1994 Thymic and extrathymic origins of gut intraepithelial lymphocyte populations in mice. J Exp Med 180:681-686 